\title{
Ballesteros, Jesús. Domeñar las finanzas, cuidar la naturaleza. Valencia: Tirant lo Blanch, 2021.
}

\author{
Vicente Bellver Capella \\ Departamento de Filosofía del Derecho y Política \\ Universitat de València
}

Fecha de recepción 26/10/2021 I De publicación: 23/12/2021

Si quien empieza a leer esta reseña conoce la obra de Jesús Ballesteros, el libro que ha publicado le procurará la gran satisfacción de tener ahora a mano una síntesis de su pensamiento a lo largo de los últimos cuarenta años. Si, por el contrario, el lector no está familiarizado con la obra del jurista y filósofo valenciano, el libro le brindará la oportunidad de acceder a lo que, a mi parecer, constituye una de las propuestas de filosofía práctica más originales y consistentes del último medio siglo. Quizá las circunstancias políticas de España en ese tiempo propiciaron la aparición de una destacada generación de pensadores del Derecho y la Política que, reflejando una amplia pluralidad de posiciones, aportaron valiosas contribuciones para entender y configurar el tiempo que les tocaba vivir. Una de ellas fue la del profesor Ballesteros. Lo que a continuación ofrezco es un esbozo de algunas de las principales ideas que atraviesan su pensamiento.

Jesús Ballesteros no se cansa de repetir que los dos problemas globales más amenazantes para la humanidad en la actualidad son la crisis ambiental y la exclusión social, y que ambos tienen su causa en el paradigma tecnocrático dominante hoy en día en el mundo. Desde principios de los años ochenta del pasado siglo se ha ido ocupando de ambos, de las causas que los han creado y de la forma de superarlos. Sus trabajos estaban dispersos en libros y artículos de revistas, algunos difíciles de encontrar. Los profesores José Sanmartín y José Alfredo Peris le propusieron publicar un libro con una selección de esos trabajos. El resultado ha sido "Domeñar las finanzas, cuidar la naturaleza", un volumen de cerca de 500 páginas cuya primera parte está centrada en la crítica del capitalismo financiero y la segunda en la crisis ambiental y las alternativas para salir de ella. 
En 1989 Ballesteros publica un libro, Postmodernidad. Decadencia o resistencia ${ }^{1}$, que sintetiza su pensamiento sobre la crisis de la Modernidad y las dos grandes alternativas postmodernas que aspiran a ocupar su lugar, a las que etiqueta con los calificativos de decadente y resistente. En ese libro aparecen tratados de forma embrionaria buena parte de los temas a los que dedicará los años siguientes de su investigación: la paz, la cuestión ambiental, el feminismo, el interculturalismo, la alternativa al capitalismo, la desmesura de la biotecnología. Frente a la postmodernidad decadente a la que nos habría abocado la Modernidad, propugnará un nuevo modelo de pensar que califica como postmodernidad resistente. Según él, la Modernidad se caracteriza porque su fascinación ante los avances de la razón científico-técnica le llevó a desconsiderar la existencia de otros usos de la razón. La consecuencia fue trágicamente empobrecedora: el conocimiento de la realidad quedó reducido al conocimiento ofrecido por las ciencias matemáticas y empíricas. Esa absolutización de la razón científica trajo consigo un efecto pendular. Se criticó que ese conocimiento no era más que un gran relato, una enorme impostura que había traído consigo las consecuencias más aciagas para la humanidad: las peores confrontaciones bélicas de la historia y una crisis ambiental difícilmente reversible. El problema es que muchos de los que plantearon esa lúcida crítica la llevaron hasta el extremo de sostener que cualquier conocimiento que pretendiera el ser humano no era más que un relato, un discurso carente de consistencia. Procedía, en consecuencia, negar la existencia de una realidad susceptible de ser conocida por el ser humano. En eso consiste la postmodernidad decadente. A falta de una realidad cognoscible por los distintos usos de la razón humana, se decreta que lo único que está al alcance de los seres humanos es construir relatos sobre la nada.

Ballesteros estará de acuerdo con esa postmodernidad en su denuncia de la razón científico-técnica como clave única de conocimiento y dirección de la acción humana. El gran relato de la Modernidad no es más que un gran engaño. Pero frente a él, y en contra de la postmodernidad decadente, Ballesteros afirma la capacidad de la razón para conocer la realidad y orientar la acción humana de acuerdo con ella. Es la postmodernidad resistente, a la que así califica porque consiste en un doble ejercicio de resistencia: frente a quienes persisten en absolutizar la razón científica y decretar la completa emancipación humana gracias al progreso tecno-científico; y frente a quienes niegan cualquier posibilidad de conocimiento a la razón humana y se resignan al nihilismo lúdico o trágico. Desde la perspectiva de esa postmodernidad

\footnotetext{
${ }^{1}$ El libro ha sido reeditado en varias ocasiones. La última es: Jesús Ballesteros, Postmodernidad. Resistencia o decadencia, Tirant lo Blanch, Valencia-Ciudad de México, 2019.
} 
resistente, Ballesteros se ocupa en el libro recién publicado de las dos las grandes crisis contemporáneas: la financiera y la ecológica. Pero, como veremos más adelante, apunta también hacia otros desafíos.

\section{Domeñar las finanzas para superar el capitalismo}

Para abordar la primera de las crisis, Ballesteros parte de la distinción fundamental entre economía de mercado y sociedad de mercado o capitalismo. La economía de mercado se caracteriza por la primacía del trabajo, la igual responsabilidad de los agentes económicos, y la subordinación de las finanzas a la economía real. La sociedad de mercado, por el contrario, se basa en la primacía de la tecnología y el capital sobre el trabajo, y de las finanzas sobre los bienes materiales. La abstracción y mecanización suplantan al mundo real: a las personas concretas y a los bienes físicos. Ese estado de cosas consagra la irresponsabilidad de los poderosos (el principio "Too big to fail”), y la sistemática exclusión de los ineficientes. Por ello, la economía de mercado y el capitalismo definidor de la sociedad de mercado no aparecen solo como algo distinto, sino más bien contradictorio. Así lo han puesto de manifiesto diferentes escuelas económicas, como el ordoliberalismo, que dan por supuesto que la economía de mercado solo puede darse en una sociedad no mercantilizada, basada en la lealtad, el trabajo, la competencia, la subsidiariedad y la solidaridad. Todo ello desaparece en la sociedad de mercado. Ballesteros señala a las grandes empresas tecnológicas como el vivo ejemplo del primado actual de la sociedad de mercado sobre la economía de mercado. Su poder es tan hegemónico que han conseguido que los bancos, causantes de la crisis de financiera de 2008, estén en peligro de extinción como consecuencia de la capacidad depredatoria de aquellas, al operar en todos los ámbitos de la vida económica sin sujetarse a otras normas que las que ellas mismas se quieran dar.

Ballesteros señala que la sociedad de mercado se apoya en la idea del homo oeconomicus, que desprecia los conceptos tanto de creación como de procreación natural, considerada esta última como un residuo premoderno que debe ser sustituido por la reproducción artificial, sustentada en los principios de calidad, eficiencia y satisfacción del consumidor. Al mismo tiempo trata de erradicar las diferencias ontológicas entre la mujer y el varón, con la suplantación del sexo por el género, así como la diferencia entre la inteligencia humana y la mal llamada inteligencia artificial, definitoria del movimiento transhumanista.

Con tanta lucidez como contundencia, Ballesteros asegura que la globalización actual “está imponiendo la sociedad de mercado, en la que el dinero manda, y eliminando la economía de mercado, en la que el 
dinero sirve". Si queremos que la globalización se ponga al servicio de las personas y no de las finanzas, urge recuperar la economía de mercado y rechazar la sociedad de mercado.

Pero Ballesteros va más allá al sostener que esa economía de mercado adquiere su pleno sentido en el marco de lo que denomina personalismo ecológico y social y que comprende el imperativo no solo de cuidar la naturaleza en general, sino también la naturaleza humana en particular, respetando las diferencias naturales entre los seres humanos y luchando contra las desigualdades producidas por la dominación política, la explotación económica o la violencia lúdica. Ballesteros proyecta estas exigencias sobre el plano temporal y el espacial. En el plano temporal, propone sustituir la obsesión por el lucro inmediato por la sostenibilidad, que aprecia la duración y la permanencia. En cuanto al espacio, frente a la lógica de la globalización y la escalabilidad, subraya la importancia de lo pequeño y lo cercano.

En definitiva, para recuperar la cordura y orientar adecuadamente nuestras relaciones con la naturaleza en sentido amplio, el filósofo valenciano propone que reconozcamos las diferencias propias del ser humano al tiempo que luchamos contra las desigualdades entre los seres humanos; en definitiva, que reemplacemos la cultura de la abstracción y el descarte por la cultura del reconocimiento y el imperativo del cuidado.

\section{La naturaleza: ni severa madrastra, ni una esclava generosa}

En la segunda parte del libro Ballesteros se centra en identificar las causas de la crisis ecológica y en articular su alternativa de un ecologismo como si la gente importara, en la línea de Schumacher.

El poder generado por la tecnociencia en el siglo XX ha convertido al ser humano en un agente ecológico planetario. Los efectos de sus acciones alcanzan a todos los rincones de la Tierra y transforman de forma duradera e imprevisible los sistemas naturales. No es exagerado afirmar que la naturaleza, entendida como una realidad viva que evoluciona al margen de influencias humanas, ha desaparecido de manera irreversible. La sustituye la socionaturaleza, en la que los procesos naturales están inseparablemente imbricados con las acciones humanas. En la medida en que esa huella humana empieza a quedar reflejada en la composición geológica de la tierra se dice que hemos pasado a una nueva era geológica, el Antropoceno, que reemplaza al Holoceno, el periodo geológico de los últimos 12000 años.

Justo cuando el ser humano se ufanaba de haber sometido la naturaleza a su servicio, los efectos colaterales de ese "dominio" manifiestan una gravedad e incertidumbre que parecen desbordar los 
beneficios alcanzados. El daño infligido a la naturaleza se vuelve contra el propio ser humano. Este discurso alarmista ha caracterizado al movimiento ecologista desde sus inicios y le ha reportado algunos de los efectos contraproducentes que le son propios: de la eficacia explosiva inicial pronto se pasa a la indiferencia o incluso al rechazo social al constatar una y otra vez que los peores presagios nunca se cumplen. En todo caso, la evidencia científica de un nuevo universo socionatural nos interpela a nivel personal y colectivo, exigiendo de nosotros una respuesta ética y política.

Ante este desafío inédito en la historia de la humanidad, Ballesteros identifica tres respuestas alternativas: acelerar el proceso del control humano sobre la naturaleza (paradigma tecnocrático); revertir la situación presente para volver a un estadio en que la naturaleza recupere su independencia respecto de la acción humana (decrecentismo); y mantener el sistema como hasta ahora con los ajustes que se precisen para sortear los efectos colaterales (ecocapitalismo). Ninguna de estas opciones le resulta satisfactoria.

a) El paradigma tecnocrático defiende que la solución a las disfuncionalidades creadas por la acción humana consiste en acelerar el proceso de dominio tecnológico sobre la evolución natural. Las expresiones más visibles de esta propuesta serían la geoingeniería, a nivel planetario, o el posthumanismo a nivel de la especie humana. Puesto que la naturaleza carece de cualquier significado y valor por sí misma, y el poder tecnológico puede alcanzar un potencial ilimitado para configurar el mundo material, debemos abandonar las actitudes miedosas, y decidirnos a asumir en plenitud nuestra capacidad de controlar y mejorar la evolución del mundo (John Harris) de acuerdo con el principio de proacción (Steve Fuller). Para Ballesteros, la pretensión de atribuirse la capacidad del dominio total sobre la naturaleza no solo es un ejercicio de arrogancia infantil sino una agresión a la propia condición humana y a las bases ambientales para su desarrollo.

b) El decrecentismo entiende que el modo de vida actual y/o el número de seres humanos que habitan la tierra resultan insostenibles porque existen unos límites y equilibrios naturales que, si se alteran, harán imposible la vida humana sobre la tierra. Aboga, en consecuencia, por reducir el crecimiento económico, el demográfico o ambos. Según Ballesteros, esta propuesta acierta al reconocer que el problema es el modelo de desarrollo basado en el capitalismo financiero desregulado, que provoca por igual la explotación de las personas y la degradación del medio ambiente. Sin embargo, el decrecentismo no repara en la necesidad y las posibilidades del desarrollo tecnológico para garantizar una vida digna a los seres humanos presentes y futuros. Si existe un derecho al desarrollo de todas las personas y los pueblos (en particular, de aquellos que no cuentan con los recursos para alcanzarlo), existe un deber correlativo 
de crear las condiciones para alcanzarlo, lo que supone poner la tecnología al servicio de ese objetivo. La versión extrema del planteamiento decrecentista la encontramos en movimientos como la DeepEcology o el primitivismo, que nos presentan al ser humano como un peligroso depredador y a la naturaleza como una severa madrastra ante la que solo cabe sumisión. Nada tiene que ver este planteamiento con el que contempla la naturaleza como un jardín que debamos cultivar responsablemente (Chesterton, Byung-Chul Han).

c) El ecocapitalismo es la versión verde del sistema económico dominante. Sin cuestionar el modelo social y económico basado en el auto-interés, reconoce los límites del crecimiento. Pero mantiene la convicción de que se puede desarrollar un sistema productivo sostenible que resuelva los problemas ambientales del presente mediante la innovación tecnológica y sin necesidad de hacer cambios en el modelo capitalista. Propuestas tan variadas como la modernización ecológica, la economía verde o la economía circular coinciden en defender la validez tanto del sistema capitalista como de la tecnología para combatir la degradación ambiental y reducir la pobreza. La Agenda 2030 sobre los Objetivos del Desarrollo Sostenible estaría en esta línea de entender compatible el crecimiento económico sostenido con la sostenibilidad económica y ambiental. Hasta el momento, la aplicación de estos modelos se ha limitado a determinados países o regiones, logrando que sus procesos productivos sean más sostenibles. Pero el resultado global está lejos de ser alcanzado: la especulación financiera y los beneficios inmediatos siguen siendo los vectores principales del sistema económico, en menoscabo de las personas y la naturaleza.

El paradigma tecnocrático tiende a desconocer el valor de la persona y los límites de la naturaleza. El decrecentismo tiende a olvidar la urgente necesidad de poner la tecnología al servicio de unas condiciones de vida dignas para toda la humanidad. Y el ecocapitalismo es la versión contemporánea de un modelo económico que se globalizó en el siglo XX, que genera tanto crecimiento como desigualdad y deterioro ambiental, y que se reformula permanentemente para legitimarse y mantener su hegemonía. Los dos primeros son modelos ideales que están más presentes en los libros que en la realidad; el tercero, que combina elementos de los dos anteriores, es el que rige la vida de la mayor parte de la humanidad de forma continuada desde hace más de setenta años. Como dice Jameson "it seems to be easier for us today to imagine the thoroughgoing deterioration of the earth and of nature than the breakdown of late capitalism". Pero, a diferencia del pensador postmoderno estadounidense, como se verá a continuación, 
Ballesteros rechaza la idea de la inevitabilidad de la historia y ofrece una propuesta que, por estar basada en la comprensión de la realidad, contiene un horizonte de esperanza.

\section{Justicia ecológica en el Antropoceno}

Según el profesor valenciano, más allá de las limitaciones específicas de cada una de las respuestas mencionadas, todas comparten un error de base: la consideración marginal del ser humano. En el paradigma tecnocrático se considera que el ser humano es un algoritmo biológico bastante deficiente (Yuval Harari) en tránsito hacia la posthumanidad. El decrecentismo corre el riesgo de otorgar mayor valor a la naturaleza que a cada ser humano y a la familia humana en su conjunto. Por último, el ecocapitalismo no acaba de abandonar la consideración del ser humano como un individuo intercambiable y no como un ser único y valioso por sí mismo.

Para dejar atrás la crisis ecológica, que multiplica tanto las desigualdades entre las personas como los riesgos para las condiciones de vida de las futuras generaciones, es necesario poner a la persona como centro de consideración. Lo primero será reconocer nuestra dependencia de la naturaleza y, al mismo tiempo, la responsabilidad que tenemos de cuidarla. Este reconocimiento debe conducir a una visión de la justicia simultáneamente sincrónica (para con todos los seres humanos actuales) y diacrónica (entre las generaciones presentes y futuras), que supere el contractualismo dominante.

Tanto el paradigma tecnocrático como el ecocapitalismo abrazan con entusiasmo la idolatría tecnológica, al confiar completamente en ella como respuesta a los males que nos afligen. La tecnolatría (Ernesto Sábato) proclama que la emancipación humana se alcanzará por medio la innovación tecnológica sin límites sobre una naturaleza reducida a la condición de esclava generosa. Por ello, Ballesteros está convencido de que el gran reto de la justicia y el Derecho en el presente consiste en defender al ser humano frente al poder incontrolado de la tecnología en cuatro áreas de ingeniería. La ingeniería industrial debe superar definitivamente la degradación del medio ambiente causada por el deterioro de los recursos naturales; la ingeniería financiera debe superar la fuga de la economía hacia la virtualidad a través de instrumentos financieros fraudulentos, que hacen inviable la economía real; la ingeniería biotecnológica debe superar la ley del deseo soberano por el reconocimiento agradecido ante lo dado; y la ingeniería digital debe ponerse al servicio de las necesidades humanas y no de la instrumentalización de los humanos para el lucro de las grandes tecnológicas. 


\section{Nuevos ropajes para la antigua Gnosis}

Para desactivar el paradigma tecnocrático que está a la base del capitalismo (también en su fórmula ecológica) Ballesteros considera necesario indagar en la concepción filosófica que lo sustenta y que es la vieja filosofía del gnosticismo, revestida con nuevos ropajes. La antigua gnosis rechazaba el mundo creado porque sostenía que era obra de un demiurgo perverso que buscaba la perdición de la humanidad. El gnosticismo actual mantiene el rechazo a la idea de creación pero, al mismo tiempo, confía ciegamente en que puede ser superada gracias al progreso técnico. El desprecio a la idea de creación conduce a total homologación de lo real a través de las matemáticas, la informática y el dinero. Nada existe en la realidad que no pueda reducirse a número, y convertirse así en objeto enteramente manipulable.

La sombra del neo-gnosticismo se proyecta de forma preocupante tanto en la relación del ser humano con el resto de los animales como consigo mismo y con los dispositivos dotados de inteligencia artificial.

Si la creación es despreciable, puesto que el ser humano forma parte de ella como criatura que es, carece de sentido otorgarle un estatuto privilegiado y atribuirle cualidades que lo singularicen y lo eleven por encima del resto de los animales. En consecuencia, cualquier diferencia de trato entre seres humanos y animales no humanos será tenida como una forma de discriminación por razón de la especie, lo que se denomina "especismo". Ballesteros afirma que los seres humanos son seres vivos materiales pero, a diferencia de todos los demás, son los únicos capaces de hacerse cargo de la creación y cuidarla: son los únicos que pueden responder. En consecuencia, el trato respetuoso hacia los animales no es principalmente para que nos rindan un beneficio sostenido a lo largo del tiempo, ni para evitarles un trato impropio de nuestra condición. Es expresión del deber de cuidado que tenemos ante unos seres valiosos por sí mismos.

Puesto que el ser humano carece de valor por sí mismo, no hay nada que deba preservarse en él y, en consecuencia, toda suerte de intervención sobre uno que contribuya a satisfacer sus deseos será lícita. El cuerpo no forma parte de mi ser sino de mi tener, de las cosas que poseo soberanamente. Ballesteros, por el contrario, afirma que nuestra condición corporal revela una forma de ser en el mundo según la cual el respeto a uno mismo alcanza la totalidad de nuestro ser y no solo a nuestra voluntad autónoma, que no es más que una abstracción. 
Por último, el neo-gnosticismo asume que la inteligencia humana, fruto de la creación, es inferior que la inteligencia artificial obra de su propio ingenio. El ser humano se ve presa de una "vergüenza prometeica" (Günther Anders) al constatar que sus propias creaciones tecnológicas resultan muy superiores a él mismo. Sentirá entonces la urgencia de superar la maldición del mundo creado, incluyendo al propio ser humano como criatura, mediante la confianza ciega en las posibilidades de la tecnología para crear un mundo radicalmente nuevo y un ser posthumano que sancione la obsolescencia del ser humano. Frente a ello, Ballesteros rechaza de plano la comparativa entre una inteligencia frágil pero genuina, y unos algoritmos extraordinariamente eficientes pero incapaces de penetrar el sentido profundo de las cosas. 